\title{
National Salvation through Medicine: Sichuan Provincial Health Bureau and the Allocation of Medical Resources Donated by American Red Cross-A Case Study of Chengdu during Anti-Japanese War
}

\author{
Shiqi Yu \\ College of History and Culture, Sichuan University, Chengdu, Sichuan Province, China
}

Keywords: Anti-Japanese War, American Red Cross, medical resources allocation.

\begin{abstract}
After the Anti-Japanese War broke out, the strategic position of Sichuan Province was established. In order to consolidate the rear area, to train a large number of medical personnel and strive for victory, the national government began to pay attention to the medical and health undertakings of Sichuan province. During wartime, there were acute shortages in medical supplies. Medical equipment and medicines donated by American Red Cross were important resources for the war of resistance, and played an important role in the rescue of sick and wounded. Sichuan Provincial Health Bureau had the power to allocate these medical resources. In Chengdu, about 100 units submitted applications for medical assistance. When distributing medical devices and medicines, the Health Bureau not only paid attention to their actual needs, but also considered the actual storage situation. Though overall planning, Sichuan Provincial Health Bureau provided all units in Chengdu with different medical and health recourses, and helped them to prevent diseases and cure patients.
\end{abstract}

\section{Introduction}

Medical and health undertakings are concerned with national economy and people's livelihood, and should be taken seriously. In the vast interior area of the western part of China, medical issue had been neglected for a long time. In November 1937, the capital was officially moved to Chongqing; the strategic position of Sichuan province was established. In order to strengthen the protection efforts and cultivate healthy citizens, it was imperative to develop medical and health undertakings in Sichuan province. In the context of the war of resistance, Sichuan Provincial Health Bureau was set up to build and manage the medical and health industry of Sichuan. Chengdu, as the capital of Sichuan Province, was the representative of Chengdu's medical and health construction at that time.

\section{Establishment of Sichuan Provincial Health Bureau and Medical Resource Allocation Principles}

In May 17, 1939, Sichuan Provincial Health Bureau was established in the city of Chengdu. It belonged to the Civil Affairs Department. An expert on public health, Zhi-qian Chen, was appointed as the director. There were four departments in the Health Bureau, namely administration office, technical office, general affairs department and secretary. The position of Health Bureau was decided by the location of Chengdu. Chengdu, as the capital of Sichuan, took the lead of the whole province. Moreover, Chengdu was under the supervision of Chairman Jiang; it was also a city which attracts tourists all over the world. With the support and input from the central government, health undertakings in Sichuan province were carried out smoothly. The Sichuan Provincial Health Bureau drawn up detailed work plans since its establishment. Apart from government's funding and financial assistance, as well as the overall planning and personnel dispatch, medical resources were most important for the Health Bureau. The health undertakings in Sichuan province were established and developed under a special background; they had neither firm foundation nor enough medicinal 
materials. Therefore, the assistance from allies was crucial. The American Red Cross continued to supply medical instruments to Sichuan during and after the war. But during the war of resistance, the allocation of sources was blocked by traffic difficulties. Thus, authorities intended to build a medical materials plant which could provide medical materials continuously. The medical materials factory was the place where all medical resources were kept, including medical materials supplied by American Red Cross and resources produced at home.

For medicines and instruments donated by American Red Cross, the Health Bureau had clear principles on their storage and distribution. The distribution principle was equal allocation, but for counties which did not have convenient traffic conditions and insufficient purchase sources, and areas which were often attacked by air raid, more resources were provided. Donated medicines could not be charged or resold. They must be used in free diagnosis and treat, and the medical objects must be refugees, injured people, survivors from attacks, family members of soldiers, and people who become poor because of war or disasters. These principles ensured the nature of public benefit of American Red Cross, which distinguish it from other medical rescue institutions.

For the storage of drugs and medicinal instruments, the emphasis was placed on their memorial and identification functions. All containers labels, restricted bags, beds and sheets were marked with "donations from American Red Cross". Each unit which received donated instruments should promptly report the distribution list and usage of these resources to the Health Bureau for follow-up checks.

\section{Sichuan Provincial Health Bureau's Allocation of Medical Resources Donated by American Red Cross}

Since the Sino Japanese war broke out, American Red Cross began to provide free medical resources. Firstly, American Red Cross sent all these resources to the Sichuan Provincial Health Bureau, and deposited them into the medical materials factory, a health service organization subordinate to Sichuan Provincial Health Bureau. When applications for drugs and equipments were put forward by different units, the Materials Distribution Committee would hold a meeting to discuss these applications and decide how to distribute medical materials. Later, applicant units could go to the medical materials factory and get resources through the notes issued by the Health Bureau. In accordance with related requirements, they should record the number of patients and the treatment effects of these materials, and submit the feedback lists to the Health Bureau. For different units, the medication and treatment applications are different.

Since the wars of resistance, 95 public and private units were established in Chengdu, including 22 health service units and 73 other kinds of units. Their applications can be divided into two types. 1 . All medical resources mentioned in the application were granted by the Health Bureau. 2. Some medical resources mentioned in the application were granted by the Health Bureau. Some materials are distributed in fewer quantities, while the requirements of some resources are rejected "for there was no inventory on these drugs or medical devices". From the perspective of application for drugs, it can be found that medical institutions mainly applied for more equipments and relatively diversified drugs; non medical institutions often applied for commonly used medicine, such as cold cure and ant malarial agents, their applications were in small numbers and single variety.

Sichuan Provincial Health Bureau allocated 10 units as Sichuan provincial health service units. These units were highly valued by the Health Bureau, and became the focus of medical development in Sichuan Province. They took advantages in medical materials distribution. The Health Bureau approved all their applications. The First, Second and Third Nursery of Chengdu were provincial health service organizations, shouldering the responsibilities of maternal and child health care, birth statistics and the delivery of babies. They applied for drugs and medical devices to Sichuan Provincial Health Bureau all the year round. Since the war of resistance against Japan, hospitals received more and more sick and wounded citizens and soldiers; their demands for drugs increased. In January 1944, three nurseries of Chengdu applied for 5 pounds, 20 pounds and 6 pounds of cotton to Sichuan Provincial Health Bureau respectively. The Sichuan Provincial Health Bureau met the requirements of three nurseries, and allocated 6 pounds of cotton for each nursery. In January 1947, The First 
Nursery of Chengdu applied for 10 pounds of cotton, 10 forceps, 10 pairs of gloves, 20 empty needles for 2cc, 1 sphygmomanometer and 1 stethoscope. Zhi-qian Chen, the director of the Sichuan Provincial Health Bureau, immediately replied, "granting distribution of 5 pounds of cotton, 4 forceps, 5 pairs of gloves, 20 empty needles for 2cc and 1 stethoscope." Through their contacts with the Sichuan Provincial Health Bureau, it can be seen that the requirements for medical equipment and drugs from nurseries were always satisfied. To a certain extent, the Health Bureau solved difficulties for these medical units, and eased the shortage situation in the flames of war.

Sichuan Provincial Maternity and Infant Health Institute and Fu Cheng Hospital also belonged to health service unit. There were total 12 health service units. Sichuan Provincial Health Bureau always responded to their requests selectively. In June 1946, Sichuan Provincial Maternal and Infant Health Institute applied "for two thousand grains of sulfathiazole donated by the American Red Cross for the benefit of poor patients." The Sichuan Provincial Health Bureau replied in July, "granting issuing one thousand grains of sulfathiazole". Health Bureau's attitude towards these units can be found. The Health Bureau basically approved their applications, but there were great differences in the quantities of drugs and medical devices between application and allocation. The Health Bureau's responses were not timely, indicating that the Health Bureau did not pay much attention to these units.

Apart from health service units, there were 74 other kinds of units, which were also facing the situation of doctors and medicine shortage, especially in the period of epidemic. When staffs and students need drugs, these units had to constantly apply for medicine to the Health Bureau. Since flu was frequently outbreak among employees and school students, these units often applied for common medicines such as quinine pills and aspirin. Sichuan Provincial Accountant School applied in September 1944 to the Health Bureau, because they have "run out of drugs offered by the Health Bureau and the number of students is increasing. The limited budget prevents us from buying more drugs. This is a list of drugs required by us; please continue to help us." Health Bureau replied in October of the same year, "the nineteenth meeting of Committee agreed to distribute 500 grains of aspirin, 500 grains of quinine pill tablets, 100 antiphlogistic tablets, 500 Blanc's tablets, $50 \mathrm{~g}$ of iodine, 1 pounds of Vaseline, $50 \mathrm{~g}$ of salicylic acid, 1 pound of cotton and 1 pound of gauze." We can see that, drugs applied by academies were commonly used drugs, mainly for the treatment of common diseases. Generally speaking, the Health Bureau could meet some of their requirements. As long as there were enough drugs, the Health Bureau would offer them to these units. The health of the people is related to the safety of the country and the future of the nation. It is necessary to create a good hygienic environment and strengthen people's physical condition, so as to better serve the war of resistance and the further construction. The drugs offered by American Red Cross alleviated people's suffering from disease, and changed the health environment.

\section{Treatment Condition and Significance of Drugs and Equipment Donated by the Red Cross}

During the war, some units failed to report the treatment results of received medical instruments and the number of patients to the Health Bureau. Only a handful of health service units provided statistics data on the number of people treated. 
Table 1 Number of patients of each unit treated by medicine and equipment donated by Red Cross

\begin{tabular}{|c|c|c|}
\hline unit & time & Number of patients \\
\hline No.1 Nursery of Chengdu & $\begin{array}{l}\text { May-- December, } 1944 \\
\text { October, } 1946\end{array}$ & 586 \\
\hline No.2 Nursery of Chengdu & $\begin{array}{l}\text { July, 1944—June,1945 } \\
\text { July—December, } 1945\end{array}$ & 4297 \\
\hline $\begin{array}{l}\text { Maternity and Infant Health Institute } \\
\text { of Sichuan }\end{array}$ & January_-December,1946 January, 1947 & 8545 \\
\hline Pu Cheng Hospital & January- May, 1944 & 41 \\
\hline $\begin{array}{l}\text { Training School for Public Health } \\
\text { Nurses }\end{array}$ & July, 1946 & 25 \\
\hline Civil Servants' Clinic & $\begin{array}{l}\text { June, July, September of } 1944 \\
\text { May-June, } 1945\end{array}$ & 2109 \\
\hline $\begin{array}{l}\text { Infectious Disease Hospital of } \\
\text { Sichuan }\end{array}$ & $\begin{array}{l}\text { July,1943-June,1944 } \\
\text { July, 1945—June,1946 } \\
\text { July, 1947-June,1948 } \\
\text { July, 1948_-June,1949 }\end{array}$ & 2921 \\
\hline Sichuan Provincial Hospital & August- November, 1947 & 255 \\
\hline $\begin{array}{l}\text { Chengdu Sanitation Affairs } \\
\text { Institute }\end{array}$ & May, 1945 & 838 \\
\hline $\begin{array}{l}\text { Sichuan Provincial } \\
\text { Accountant School }\end{array}$ & $\begin{array}{l}\text { January, 1944-- January,1945 February - } \\
\text { June, } 1945\end{array}$ & 141 \\
\hline Factory for Military Dependents & April - July, 1944 & 991 \\
\hline Chengcheng Middle School & April - June, 1945 & 38 \\
\hline No.1 Prison of Sichuan & October, 1944 & 117 \\
\hline Total & \multicolumn{2}{|l|}{20904 patients } \\
\hline
\end{tabular}

From the recorded data it can be seen, there were only 13 units which reported the usage of drugs and treatment equipment donated by American Red Cross, including 9 health service institutions, and 4 other kinds of institutions. The total number of patients treated by 13 units was 20904, and the records were follows. 1. The total number of patients reported by health service institutions was significantly higher than other kinds of institutions. 2. Statistical treatment data reported by health service institutions was more comprehensive and accurate than that of other kinds of institutions. Monthly reports were commonly seen in health service institutions. 3. In these statistic reports, the biggest problems were incomplete and non continuous data. At that time, statistical treatment was not a routine task in medical affairs. In these submitted monthly reports, statistical problems include incomplete and discontinuous data were also obvious. 


\section{Wartime Features of Medical Resources Allocation}

During this period, American Red Cross and Sichuan Provincial Health Bureau's medical resources distribution had following characteristics.

The primary task was to provide commonly used drugs for free. The medical conditions in Sichuan were backward, and people's diseases often got worse because the patients were not treated correctly. This problem attracted the attention of the government during the war, and the authority began to use foreign aid to improve local medical conditions. During this period, drugs granted by the American Red Cross were limited in species and small in number; they were inadequate to distribute, and treatment effects were impaired. Quinine pills and aspirin were most common medicines. During the period of the Republic, medical conditions in Sichuan were poor, and people did not pay attention to personal hygiene habits; they were vulnerable to disease. Widespread cross infections often led to various epidemic diseases, while the frequent outbreaks of epidemic serious threatened people's lives. During the Anti Japanese War, a large number of soldiers' health conditions were damaged. National unity and social stability were difficult to maintain. The control of malaria became an urgent issue for the authority.

Uneven distribution; there were great differences in the quantities of drugs and medical devices between application and actual distribution. In wartime, medical resources were in short supply; compared with Chengdu's demand for drugs, the donation from American Red Cross was a drop in the ocean. All units in Chengdu City applied for medical instruments to the Health Bureau, and the Health Bureau was unable to meet all of their requirements. The Bureau had to appropriately allocate resources according to the total amount of drugs. When drugs were scarce, even common medicines like anti-inflammatory tablets and malaria were difficult to obtain, not to mention other kind of drugs. With the increasing number of patients and the decreasing storage of medicine, the uneven distribution of drugs and the differences between application and distribution became inevitable. Thus, drugs' effects of preventing and treating disease could not be guaranteed.

\section{Conclusions}

By analyzing the medical resource allocation of Sichuan Provincial Health Bureau during the wartime, it can be found that with the enhancement of Chengdu's status, the national government began to put more efforts in the medical and health undertakings of Chengdu. The medical materials factory built in the East Third Ring of Chengdu was used to store local produced drugs and medical resources donated by American Red Cross. These drugs supported the war of resistance, protected the health of people, improved the hygienic conditions and improved people's health consciousness. But some units' demands for drugs were not satisfied, and the distribution of drugs was uneven. Medical materials' effect of disease treatment varied greatly from different units. Although the treatment outcome was not perfect, medical resources distribution during wartime took the long-term effects of laying the necessary foundation for the future development of health undertakings in Sichuan.

\section{Acknowledgements}

Fund Project: This paper is one of the outcomes of the research, Digital Processing and Research of Republican Archives in County-level Archives of Sichuan, which is supported by Foundation for Western Projects of the National Social Science Foundation of China (Project No.: I3XZS026).

\section{References}

[1] Sichuan Province Archives, Brief Work Reports of Sichuan Provincial Health Bureau, record group number: 0113, catalog number: 0002, files ID: 2628 
[2] Sichuan Province Archives: Health Authorities' Storage and Allocation Principles for Medical Recourses provided by American Red Cross, record group number: 0113, catalog number: 0001, files ID: 0009

[3] Sichuan Province Archives, Lists of American Red Cross donation received by county and provincial hospitals, and the instructions of Sichuan Provincial Health Bureau, record group 113, catalog number: 02, files ID. 2585

[4] Sichuan Province Archives, Monthly reports on number of patients treated by medicine and equipment donated by Red Cross from provincial health care clinics, other civil service units and county level clinics like Lifan and Xinfan, record group 0113, catalogue number 0001, files ID. 1373

[5] L. Zhang, M. Guo, Research on medical aid to Sichuan from allies during the war of resistance, J. Sichuan Archives, 4(2010).

[6] H.H. Li, Q.K. Li, Medical assistances to China from the international community during Anti Japanese War, J. Academic Journal of Zhongzhou. 10(2015). 